\title{
CONSTRUÇÃO DE UM MODELO TEÓRICO SOBRE O CUIDAR DA PESSOA COM TUBERCULOSE NA PERSPECTIVA DA GROUNDED THEORY ${ }^{1}$
}

\section{CONSTRUCTION OF A THEORETICAL MODEL ON TAKING CARE OF TUBERCULOSIS IN THE PERSPECTIVE OF GROUNDED THEORY}

\author{
Elisângela Franco de Oliveira Calvacante ${ }^{2}$ \\ Denise Maria Guerreiro Vieira da Silva ${ }^{3}$ \\ Gracimary Alves Teixeira ${ }^{4}$ \\ Jovanka Bittencourt Leite de Carvalho ${ }^{5}$ \\ Flavio Cesar Bezerra da Silva ${ }^{6}$
}

\begin{abstract}
Resumo: A Grounded theory possibilita a construção de uma teoria substantiva, abstraindo dados de casos a conceitos, convertendo-os num conjunto de afirmações que elucidam os acontecimentos. Este artigo objetiva descrever a elaboração de modelo teórico sobre o processo de cuidado à pessoa com tuberculose a partir dos pressupostos metodológicos da Grounded theory, segundo Anselm Strauss e Juliet Corbin. O número de participantes deu-se pela amostragem e saturação teórica, originando quatro grupos amostrais, por meio de questionamentos e análise comparativa dos dados. A coleta e análise ocorreram simultaneamente. Na codificação, teve-se: codificação aberta; codificação axial, regrupando conceitos em torno de assunto comum, originou-se as categorias e subcategorias; e com o refinamento e integração das categorias, chegou-se à codificação seletiva, e construção do modelo teórico. O modelo teórico elaborado constitui uma representação do fenômeno "cuidando da pessoa com tuberculose na atenção básica de saúde". Configuram-se, neste modelo, as categorias referentes às condições causais, às interventoras, às contextuais, às ações/interações e às consequências deste fenômeno.
\end{abstract}

Palavras-chave: Grounded theory; Pesquisa Qualitativa; Modelos de Enfermagem; Tuberculose.

\begin{abstract}
Grounded theory enables the construction of a substantive theory, abstracting data from cases to concepts, converting them into a set of statements that elucidate events. This article aims to describe the elaboration of a theoretical model about the process of care of the person with tuberculosis, based on the methodological assumptions of Grounded Theory, according to Anselm Strauss and Juliet Corbin. The number of participants was given by sampling and theoretical saturation, giving rise to four sample groups, through questioning and comparative analysis of the data. Collection and analysis occurred simultaneously.
\end{abstract}

\footnotetext{
${ }^{1}$ Este texto é um aprofundamento de uma publicação do CIAQ 2018, oriundo de uma pesquisa.

${ }^{2}$ Doutora em Enfermagem pela Universidade Federal de Santa Catarina (UFSC). Professora do Programa de Pós-Graduação em Saúde e Sociedade da Escola de Saúde da Universidade Federal do Rio Grande do Norte (ESUFRN), Natal, Rio grande do Norte, Brasil E-mail: elisangelafranco2@ gmail.com ${ }^{3}$ Doutora em Enfermagem pela Universidade Federal de Santa Catarina (UFSC). Professora aposentada do Programa de Pós-Graduação em Enfermagem da Universidade Federal de Santa Catarina, Florianópolis, Santa Catarina, Brasil. E-mail: denise_guerreiro@ hotmail.com

${ }^{4}$ Doutoranda em Enfermagem pela Universidade Federal do Rio Grande do Norte (UFRN). Professora da Escola de Saúde da Universidade Federal do Rio Grande do Norte (ESUFRN), Natal, Rio grande do Norte, Brasil. E-mail: gracimaryalves@yahoo.com.br

${ }_{5}^{5}$ Doutora em Enfermagem pela Universidade Federal do Rio Grande do Norte (UFRN). Professora do Programa de Pós-Graduação em Saúde e Sociedade da Escola de Saúde da Universidade Federal do Rio Grande do Norte (ESUFRN), Natal, Rio grande do Norte, Brasil. E-mail: jovanka@es.ufrn.br

${ }^{6}$ Doutor em Enfermagem pela Universidade Federal do Rio Grande do Norte (UFRN). Professor da Escola de Saúde da Universidade Federal do Rio Grande do Norte (ESUFRN), Natal, Rio grande do Norte, Brasil. E-mail: flavio@es.ufrn.br
} 
In the coding, we had: open coding; axial encoding, regrouping concepts around the common subject, the categories and subcategories originated; and with the refinement and integration of the categories, we came to the selective codification, and construction of the theoretical model. The theoretical model elaborated constitutes a representation of the phenomenon "taking care of the person with tuberculosis in basic health care". In this model, the categories referring to the causal conditions, the interveners, the contexts, the actions / interactions and the consequences of this phenomenon.

Keywords: Grounded Theory; Qualitative Research; Models, Nursing; Tuberculosis.

\section{Introdução}

Atualmente, considera-se o efetivo controle da tuberculose (TB) um indicativo de qualidade da atenção à saúde, remetendo, também, às questões de justiça social. A melhor estimativa, globalmente, é que 10,0 milhões de pessoas desenvolveram TB em 2017, sendo 5,8 milhões de homens, 3,2 milhões de mulheres e 1,0 milhão de crianças. Na luta de combate à doença, permanecem os desafios de promover o acesso ao diagnóstico e tratamento, e a qualidade que a assistência demanda a fim de alcançar a cura e a saúde das pessoas acometidas (BARREIRA, 2018; PELISSARI et al., 2018; WHO, 2018).

O número de mortes por TB também ainda se apresenta expressivo, em 2017, em todo mundo, a tuberculose causou cerca de 1,3 milhões de mortes em pessoas HIV negativas, a maioria dessas mortes poderia ser evitável. Existe, ainda, a preocupação com a resistência bacteriana, a incidência e a mortalidade entre as pessoas com HIV, a necessidade de garantir um tratamento diretamente observado, a melhoria do cuidado à saúde, e o enfrentamento das condições precárias de vida das pessoas acometidas (BARREIRA, 2018; PELISSARI et al., 2018; WHO, 2018).

Os enfermeiros, que, historicamente, são os profissionais mais envolvidos no cuidado às pessoas com TB, têm se deparado com situações complexas e diversificadas e desenvolvido variadas formas de superar essas situações, que nem sempre constam nos manuais e textos sobre a atenção às pessoas com TB. Nesse sentido, estudos que buscam apreender como o cuidado vem sendo realizado, na perspectiva desses profissionais, passam a ter uma importância especial pela possibilidade de sistematizar esses saberes e práticas, construindo um novo conhecimento em saúde.

No contexto da atuação do enfermeiro no cuidado à pessoa com TB, faz-se importante compreender as relações que se estabelecem em torno do processo de cuidar na perspectiva do profissional de enfermagem. Isto pode possibilitar reflexões e mudanças nas práticas do cuidado e revisão das práticas de saúde na perspectiva da promoção da saúde de pessoas com TB no viver mais saudável. 
A atenção às pessoas com TB demanda um cuidado prolongado e que é influenciado por diferentes aspectos, tanto relacionados à pessoa com TB, e sua condição de vida, muitas vezes em situações de vulnerabilidade social, quanto aos relacionados aos serviços de saúde (BRASIL, 2011; WHO, 2018). Desse modo, percebe-se que o processo de cuidar da pessoa com TB envolve mais do que a entrega de medicamentos e a realização de exames. Há necessidade de um envolvimento efetivo dos profissionais da saúde no cuidado, de forma a compreender as repercussões da doença em suas vidas e dos fatores que podem interferir no tratamento, contribuindo para a realização de um cuidado contextualizado à realidade de cada um.

Considerando este cenário de cuidado da pessoa com TB na atenção básica de saúde, temos nos questionado sobre vários aspectos: Como tem sido o a interação entre os enfermeiros e as pessoas com TB? Essa interação tem permitido prevenir e controlar a doença? A atuação dos enfermeiros tem contribuído para a promoção da saúde ou para um viver mais saudável das pessoas envolvidas no contexto da TB? A enfermagem está preparada para atuar na complexidade que envolve o cuidado às pessoas com TB? As condições de trabalho têm permitido uma atuação eficaz? Quais são os principais medos e estigmas destes profissionais? Eles se consideram preparados para atuar dentro dos princípios que regem o SUS? Como se concretiza o cuidar de pessoas em condição crônica de saúde quando esta se revela como uma doença infecciosa e contagiosa? Os enfermeiros têm obtido sucesso ao lidar com pessoas com TB?

Para responder essas questões, acreditamos que a melhor abordagem seria uma pesquisa qualitativa, que permitisse não somente responder a essas questões, mas que também possibilitasse uma construção teórica mais sistemática, envolvendo toda a complexidade do cuidado que o enfermeiro realiza na atenção básica, mais especificamente, o cuidado à pessoa com TB.

Portanto, a opção pela abordagem metodológica da Teoria Fundamentada nos Dados (TFD) foi uma consequência desses questionamentos, uma vez que os estudos publicados ainda são insipientes e não contemplam o processo de cuidar da pessoa com TB de uma maneira mais ampliada, incluindo as circunstâncias que favorecem ou dificultam esse processo, as estratégias de atuação frente à pessoa acometida e as consequências de toda atuação por parte dos enfermeiros.

A pesquisa desenvolvida pelo método da TFD possibilita explicar o fenômeno, com base na percepção de que as pessoas agem de acordo com os significados e que esse é definido por meio da interação. O termo "teoria fundamentada" significa que a teoria 
foi derivada de dados, os quais foram sistematicamente coletados e analisados pelo processo de pesquisa. Por ser baseada em dados, ela tende a proporcionar melhor discernimento, aprimorar o entendimento e apresentar uma orientação importante para a ação (STRAUSS; CORBIN, 2008).

A teoria, na maioria das vezes, constitui-se mais do que um conjunto de resultados, permitindo a explicação de um fenômeno. Ela tem como significado um conjunto de categorias desenvolvidas apropriadamente, que foram, sistematicamente, interrelacionadas por meio de declarações de relação para o desenvolvimento de uma estrutura teórica que elucida fenômenos relevantes (STRAUSS; CORBIN, 2008).

A TFD possibilita, então, a construção de uma teoria substantiva, que tem atributos de abstrair dados de muitos casos a conceitos, convertendo-os num conjunto de afirmações que elucidam, em sentido geral, o que está acontecendo. A teoria substantiva permite explicar um determinado fenômeno localizado em certo contexto, derivada, assim, de uma área substancial, o que a distingue de uma teoria formal. Nessa perspectiva, teoriza, significa construir, por meio dos dados, um desenho explanatório que integre, sistematicamente, diversos conceitos oriundos de declaração de relações. Essas declarações explicam quem, o que, onde, quando, por que, como e com que consequências um fenômeno ocorre (STRAUSS; CORBIN, 2008).

Assim, considera-se a TFD como método apropriado para o estudo que objetiva compreender o cuidado do enfermeiro à pessoa com $\mathrm{TB}$ na atenção básica de saúde $(\mathrm{AB})$. A TFD, diante de seu rigor metodológico para construção de conhecimentos de abordagem qualitativa, mostra-se adequada para os estudos que envolvem interações humanas e que buscam estudar fenômenos da prática da profissão que necessitam de maior compreensão.

Portanto, esse artigo objetivou descrever a elaboração de modelo teórico sobre o processo de cuidado à pessoa com tuberculose a partir dos pressupostos metodológicos da Grounded theory, segundo Anselm Strauss e Juliet Corbin.

\section{Método}

Trata-se de um estudo descritivo que apresenta a construção de modelo teórico sobre o cuidado da pessoa com TB a partir de pesquisa qualitativa que seguiu os pressupostos metodológicos da Teoria Fundamentada nos Dados (TFD), do inglês 
Grounded Theory, orientada segundo a perspectiva de Anselm Strauss e Juliet Corbin, (2008).

O cenário de estudo foi composto por oito unidades básicas de saúde, localizadas em um distrito de alta incidência de tuberculose, em uma capital do Nordeste brasileiro, considerada como município prioritário no controle da doença (CAVALCANTE; SILVA, 2013).

Participaram deste estudo 28 informantes, em quatro grupos amostrais. O primeiro grupo amostral foi composto por 19 enfermeiras que trabalhavam nas oito unidades de saúde que compuseram o cenário deste estudo. O segundo grupo amostral foi composto por duas técnicas de enfermagem, uma auxiliar de enfermagem e duas médicas, sendo uma infectologista e uma sanitarista. O terceiro grupo foi formado por duas profissionais da vigilância epidemiológica, responsáveis pela TB no distrito, uma enfermeira e uma nutricionista sanitarista. O quarto e último grupo amostral, formado por duas pessoas com tuberculose na etapa final do tratamento. Esse número foi determinado pela saturação teórica dos dados.

A coleta de dados ocorreu entre os meses de setembro de 2013 e fevereiro de 2014, por meio de entrevistas em profundidade, a partir da pergunta norteadora: Fale sobre o cuidado à pessoa com tuberculose. As entrevistas foram gravadas em áudio digital e, imediatamente após transcrição, ou seja, concomitante à coleta de dados iniciou-se a análise comparativa e o levantamento de questionamentos. Assim, foi seguido o processo de análise dos dados indicado por Strauss e Corbin (2008): codificação aberta, a axial e a seletiva. Para organização e categorização dos dados e construção de diagramas e memorandos, foi utilizado como ferramenta tecnológica o software Atlas $\mathrm{ti}^{3}$, Por se tratar de uma pesquisa, envolvendo seres humanos com manejo de seus dados e informações, a pesquisa foi submetida e aprovada pelo Comitê de Ética em Pesquisa (CEP) da Universidade Federal de Santa Catarina sob o parecer de $n^{\circ} 372.337$.

\section{Resultados}

A TFD foi a abordagem metodológica escolhida por permitir, por meio de um estudo qualitativo, a compreensão do fenômeno a partir das experiências e percepções

\footnotetext{
${ }^{3}$ Versão 7.1.8, com a licença 710CF-CAB84-3697E-8CQ81-002JY.
} 
dos participantes do estudo, usando um método rigoroso de coleta e análise dos dados, o qual respondeu, adequadamente, aos questionamentos que originaram este estudo.

Os participantes do estudo foram definidos por meio da amostragem teórica. A amostragem teórica surgiu com base nos conceitos que emergiram dos dados, objetivando explorar o escopo dimensional ou as condições diversas ao longo das quais as propriedades de conceitos variaram.

Com o início da coleta de dados, deu-se início também ao processo de análise comparativa desses dados. Esse processo permitiu a formulação de perguntas que suscitaram na necessidade de maiores esclarecimentos acerca dos depoimentos das enfermeiras, ou seja, na utilização da amostragem teórica para melhor compreensão do fenômeno em estudo. Assim, para compreender o cuidado de enfermagem à pessoa com TB na atenção básica de saúde, participaram deste estudo quatro grupos amostrais.

O primeiro grupo amostral foi composto por 19 enfermeiras da atenção básica de saúde do distrito sanitário que possuía a maior incidência da doença no município, selecionadas por suas experiências no cuidado às pessoas com TB e por aceitarem participar do estudo. Esse número foi determinado pela saturação dos dados.

O critério de inclusão do primeiro grupo amostral foi a experiência na atenção à pessoa com TB, independente do sexo. A maioria das enfermeiras das unidades básicas do distrito sanitário escolhido tinha longo tempo de atuação na Secretaria Municipal de Saúde, e na ESF, nesse município, desde sua implantação.

O segundo grupo amostral foi composto por duas técnicas de enfermagem, uma auxiliar de enfermagem e duas médicas, sendo uma infectologista e uma sanitarista. A inclusão dessas profissionais foi em decorrência dos questionamentos acerca do que vinha sendo dito pelas enfermeiras, principalmente sobre sua centralidade na atenção às pessoas com TB. Foram então levantados alguns questionamentos: Como os demais profissionais percebiam o cuidado à pessoa com TB? Será que eles também percebiam que a enfermeira é o profissional que tem papel de destaque nesse cuidado?

Também se considerou o fato de que esses profissionais geraram a expectativa de falar sobre o que estava acontecendo em outra posição que não a de ser enfermeiro, e por participarem, também, do cuidado à pessoa com TB junto às enfermeiras. Os profissionais então foram abordados sobre como ocorria o cuidado com a pessoa com TB na atenção básica, principalmente, de que modo acontecia esse cuidado naquela unidade e sua relação com a rede de serviços, verificando como ocorria o cuidado de enfermagem a essa 
pessoa, qual o papel do enfermeiro nesse cuidado e a interação deste com os demais profissionais da unidade e com a pessoa com TB.

O terceiro grupo foi formado por duas profissionais da vigilância epidemiológica, responsáveis pela TB no distrito, uma enfermeira e uma nutricionista sanitarista, incluídas após verificação, entre as enfermeiras, de que algo as incentivava a desempenhar o cuidado de enfermagem com pessoa com TB de forma bastante responsável, e que isso estava ligado, também, à gestão exercida pelo distrito.

O quarto e último grupo amostral, formado por duas pessoas na etapa final do tratamento para tuberculose, por terem o potencial de falar sobre os cuidados que a enfermeira desenvolvia e orientava. Foi abordado, nesse grupo, como tinha sido o acesso ao serviço por ocasião da doença, como tinha ocorrido todo o processo de cuidar por parte dos profissionais e da enfermeira e as expectativas, geradas por motivo de todo o tratamento.

Assim, todos os participantes integrantes do segundo, terceiro e quarto grupos amostrais foram incluídos para auxiliar a compreender alguns aspectos destacados pelas enfermeiras em sua prática de atenção às pessoas com TB. A inclusão das pessoas com TB foi decorrente da necessidade de analisar a convergência entre a perspectiva dessas pessoas e a das enfermeiras, também, com a intenção de esclarecer se o envolvimento que os enfermeiros ressaltavam ter com as pessoas com TB era percebido também por essas pessoas.

A coleta de dados ocorreu durante 6 meses, por meio de entrevistas em profundidade, a partir da questão disparadora: Fale sobre o cuidado à pessoa com tuberculose. A partir dessa pergunta inicial, eram explorados os conceitos que iam surgindo, no sentido de ampliar a compreensão acerca do que vinha sendo relatado. Por meio das afirmações dos participantes, eram levantados novos questionamentos, com o objetivo de alcançar informações a fim de obter descrição das situações e elucidar detalhes sobre o fenômeno estudado. Para o grupo das médicas e das pessoas com TB, a pergunta inicial foi apenas reformulada, porém mantendo o mesmo sentido de falar sobre esse cuidado. Com a realização das primeiras entrevistas, e suas análises, foram sendo construídos roteiros de entrevista, para cada grupo amostral que colaborou com a realização das entrevistas seguintes.

A duração de entrevista mais curta foi de 31 minutos, e a entrevista mais longa durou 1:12 minutos. A média de duração das entrevistas foi de 43 minutos. Foram gravadas em áudio digital e, imediatamente após transcrição, iniciou-se a análise 
comparativa. Para a transcrição, a pesquisadora contou com a colaboração de uma pessoa prestadora desse serviço. Após essa transcrição, a pesquisadora revia toda a entrevista, corrigia possíveis erros de terminologia e inseria as entrevistas no software atlas ti utilizado no estudo.

A análise dos dados foi efetuada concomitante à coleta de dados, utilizando como eixo norteador a análise comparativa e o levantamento de questionamentos. Para o processo de análise dos dados, ocorreu: codificação aberta, a axial e a seletiva.

Como ferramenta para organização e melhor operacionalização dos dados utilizou-se o software Atlas ti no qual permitiu o processo de codificação; inserção de memorandos relacionados aos códigos; construção de diagramas; visualização das palavras mais repetidas nos dados, que proporcionaram ideias ao pesquisador quanto ao processo que estava ocorrendo com o fenômeno em análise; como também agrupamento dos códigos.

$\mathrm{Na}$ codificação aberta os conceitos são identificados e suas propriedades e dimensões são elucidadas a partir dos dados. Sendo assim, por meio do Atlas ti, todas as entrevistas foram organizadas e codificadas linha a linha, seguindo a codificação aberta, o que permitiu originar os códigos, que conceituavam o incidente daquela fala.

Desta forma, as falas foram codificadas, e os códigos agrupados a fim de gerar grupos ou famílias que representavam conceitos sobre o fenômeno em estudo. Os códigos e grupos de códigos são ferramentas de análise dentro do software Atlas ti, como também os memorandos, que foram usados para apresentar e comentar os dados deste estudo.

Logo após o processo de codificação linha a linha, iniciou-se uma comparação em torno de assunto em comum, relacionando as categorias emergentes, o que permitiu iniciar a codificação axial, com a construção das famílias. Para tanto, como observa-se na figura 3, diagramas compostos pelos eixos temáticos representavam famílias de códigos, por apresentarem componentes analíticos semelhantes. À medida que as famílias de códigos surgiam, eram evidenciadas as categorias do estudo, resultado da análise axial, que se iniciava com o processo de reagrupamento dos dados, divididos durante a codificação aberta. Assim, as categorias eram relacionadas às suas subcategorias para levantar explicações mais precisas e completas sobre o fenômeno.

$\mathrm{Na}$ codificação axial, ocorre o processo de relacionar categorias. A Figura 3 apresenta a construção das famílias de códigos, o que possibilitava iniciar a comparação entre as famílias e a construção das categorias, as quais começavam a elucidar o esquema paradigmático proposto por Strauss e Corbin (2008). Do lado esquerdo da tela temos, de 
cima para baixo: a categoria central, as sete categorias do esquema paradigmático e logo abaixo as 24 famílias que originaram as categorias.

Figura 1: Diagrama representando graficamente uma categoria e suas subcategorias, 2014.

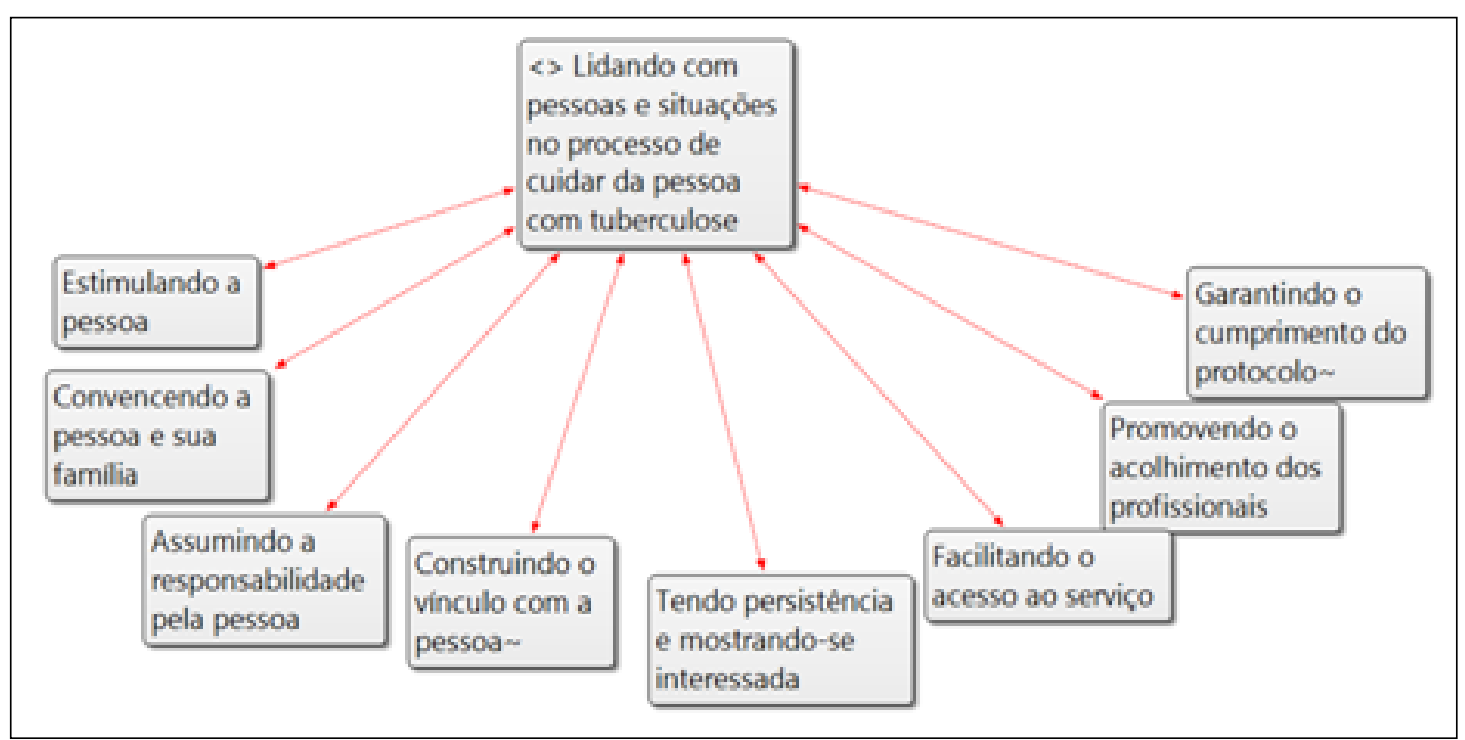

Fonte: CAVALCANTE (2014)

Durante todo esse processo analítico, foram construídos diagramas que representavam as categorias e que demostravam a ligação entre os códigos, as subcategorias e as categorias. Nele, também foi possível construir os memorandos e relacioná-los às subcategorias. Diagramas e memorandos estão apresentados na figura 1 e no quadro 2 respectivamente.

Quadro 2: Memorando escrito durante o processo de análise, Natal/RN, 2014.

Título do memorando: facilitando o acesso ao serviço da pessoa com tuberculose.

O acesso aos serviços da rede pública de saúde pelas pessoas com TB tem ocorrido inicialmente com a procura de um diagnóstico diante de uma condição clínica agudizada. Esse serviço de saúde procurado para solucionar a condição advinda da doença, febre, tosse e escarro com sangue, tem sido o hospital de referência em doenças infectocontagiosas. As enfermeiras relatam que no hospital existem meios e equipamentos instalados para dar uma resposta às pessoas com maior agilidade, ou seja, indo ao hospital a população acredita que conseguirá um diagnóstico e uma assistência capaz de resolver sua condição clínica atual. Após o diagnóstico elucidado, as pessoas são encaminhadas para a unidade básica de saúde mais próxima de sua residência, e então iniciam prontamente seu tratamento para a tuberculose.

As enfermeiras falam de formas de facilitar o acesso aos serviços dentro da unidade básica de saúde como um meio para garantir a atenção à pessoa com TB e não causar insatisfação diante de um serviço que ela irá frequentar por no mínimo seis meses. Desta forma, a pessoa com TB passa na frente dos outros, é o primeiro a ser atendido, entra na unidade e vai direto a sala da enfermeira, e fica com acesso livre para que qualquer dificuldade procurar a enfermeira. Seu prontuário é o primeiro que vai para o médico, já para ser o primeiro que o médico irá chamar.

Por outro lado, percebe-se que a prioridade a pessoa com TB também ocorre por se tratar de uma doença infectocontagiosa, que tem estigma, preconceito, cujo tratamento é difícil, que a exposição dessa pessoa é difícil, que dá vontade de abandonar quando não existem mais sintomas, e se existirem dificuldades de acesso às consultas e aos profissionais a chance de abandono é maior. Este tipo de cuidado exige um acompanhamento sem perder de vista, devido ser um tratamento antibacteriano de uma infecção transmitida por via respiratória, que pode ter desfecho fatal se não tratado, podendo acometer outras pessoas e ainda desenvolver resistência bacteriana caso a exposição a droga ocorra de forma inadequada. 
Outra forma de facilitar o acesso e garantir que esse tratamento ocorra de forma satisfatória seria ter uma equipe interessada e comprometida com a pessoa com TB e com a população como um todo.

Fonte: CAVALCANTE (2014)

Com o avanço da codificação axial e o refinamento das categorias, chegamos à codificação seletiva, que resultou na consolidação das categorias, com a confirmação da categoria central do estudo.

Durante a codificação seletiva, ocorre o processo de integrar e refinar a teoria. $\mathrm{Na}$ integração, as categorias são arranjadas em volta de um conceito explanatório central. A integração ocorre com o tempo, iniciando nos primeiros passos da análise, e, na maioria das vezes, não finaliza até a redação final. Na ocasião em que o esquema teórico seja destacado, o pesquisador está pronto para refinar a teoria, enxugando os excessos e completando as categorias mal desenvolvidas, por meio da amostragem teórica adicional.

Ao chegar nesse momento da análise, constatou-se que a categoria central do estudo era: Cuidando da pessoa com tuberculose na atenção básica de saúde, a qual representou o tema central da pesquisa. A categoria central, então, tem o poder de reunir todas as categorias para compor um todo explanatório, onde todas as categorias podem ser relacionadas a ela.

Todas as categorias estão inter-relacionadas, constituindo um processo contínuo dentro de um contexto, onde a categoria central, ou fenômeno, integra todas as circunstâncias ou condições que explicam o cuidado à pessoa com TB na atenção básica de saúde pelos enfermeiros. As categorias referentes às condições causais, às condições interventoras, às condições contextuais e às ações/interações desse fenômeno foram apresentadas em um quadro e no diagrama do modelo teórico.

O modelo teórico elaborado constitui uma representação do fenômeno "cuidando da pessoa com tuberculose na atenção básica de saúde”. Configuram-se, neste modelo, as categorias referentes às condições causais, às interventoras, às contextuais, às ações/interações e às consequências deste fenômeno, que foram respectivamente: "Tendo compromisso com a recuperação da pessoa com tuberculose", "Revelando dificuldades no cuidado da pessoa com tuberculose", "Trabalhando com pessoas e cenários no contexto da tuberculose", "Preocupando-se com pessoas com TB e as situações advindas do processo de cuidar", "Lidando com pessoas e situações no processo de cuidar da pessoa com tuberculose", "Revelando os efeitos da adesão da pessoa com tuberculose ao cuidado e tratamento" e "Revelando as implicações do abandono da pessoa com tuberculose ao cuidado e tratamento". 
Este estudo sustentou, então, a tese proposta de que o cuidado à pessoa com TB na atenção básica de saúde envolve peculiaridades individuais e sociais, demanda do enfermeiro um comprometimento e um envolvimento capazes de considerar, nas suas práticas, o contexto de vida dessa pessoa e sua família, e que têm como limitação os cenários dos serviços de saúde, que envolvem a forma de organização da rede e as condições de trabalho onde ocorre o cuidado.

O cuidado do enfermeiro ocorre por meio de uma interação entre o enfermeiro, a pessoa com TB e sua família, dentro de um contexto de adoecimento marcado por uma doença carregada de estigmas e preconceitos, e que, na maioria das vezes, acomete pessoas em situações de vulnerabilidade social. Nessa interação, foi evidenciado que as ações das enfermeiras, para que a pessoa tenha sucesso no tratamento, decorriam de sua preocupação com a pessoa com TB e das situações que permeavam essa pessoa. Essas ações estabeleceram um esforço profissional e pessoal por parte das enfermeiras, para atender as exigências e demandas da necessidade de alcançar o restabelecimento de saúde da pessoa acometida e a cura da mesma.

As peculiaridades do cuidado à pessoa com TB estão relacionadas ao contexto de vida dessa pessoa e à forma como a doença é tratada. O contexto demanda um compromisso por parte dos enfermeiros junto a essa pessoa e aos demais envolvidos no cuidado e tratamento. Tal comprometimento perpassa por três componentes: o ético/profissional, o institucional/político e o social, e foi a condição inicial para fazer o cuidado à pessoa com TB acontecer.

Consideramos que, neste estudo, o desenvolvimento do modelo teórico poderá subsidiar a construção de um modelo de cuidado de enfermagem à pessoa com $\mathrm{TB}$, que considere mais efetivamente a realidade dos serviços de saúde e que seja voltado para as demandas, necessidades e direitos da pessoa com TB em seu contexto de vida.

\section{Discussão}

A análise dos dados permitiu a construção dos conceitos. A pesquisa baseada na TFD busca descobrir o que acontece nos ambientes em estudo e como é a vida dos participantes da pesquisa. Examina-se a maneira como explicam seus enunciados e ações, assim como é discutida a compreensão analítica que podemos elaborar sobre eles (CHARMAZ, 2009). 
A TFD baseia-se nos princípios da metodologia qualitativa, e se configura como uma metodologia de campo que visa criar construtos teóricos que elucidam ação no contexto social em estudo. O pesquisador busca processos que ocorrem na cena social, tendo como guia uma série de hipóteses, que, unidas umas às outras, podem interpretar ou esclarecer o fenômeno, associando abordagens indutivas e dedutivas. Estas abordagens podem gerar teorias, cujas asserções destinam-se a sistematizar o que se sabe sobre o mundo que nos cerca (CASSIANI; CALIRI; PELÁ, 1996).

Nesse contexto, os participantes da pesquisa tendem a ser as pessoas que possuem experiências sobre o fenômeno peculiar em estudo. Assim, esses participantes são considerados os únicos especialistas em sua própria experiência (FOLEY; TIMONEM, 2018).

Destaca-se que as peculiaridades do cuidado à pessoa com TB, originadas no contexto de vida em que se inseri a pessoa com TB e da forma como é tratada sua doença, demanda um compromisso das enfermeiras para com esta pessoa. Esse compromisso, então, pode perpassar por três componentes: o ético-profissional, o institucional-político e o social, e constituem a condição inicial para fazer ocorrer o cuidado à pessoa com TB (CAVALCANTE; SILVA, 2016).

Nas pesquisas qualitativas, identificar a saturação teórica permite o pesquisador alcançar um critério determinante para interrupção da coleta de dados e definição do tamanho da amostra necessária a explicação do fenômeno estudado (NASCIMENTO et al., 2018).

Nesse processo, então, participaram do estudo 28 pessoas. Ressalta-se que, com o número de participantes, aqui apresentado, foi observada regularidade nos dados coletados e reincidência dos conceitos oriundos da análise concomitante, o que representou o ponto de saturação ou saturação teórica, proposto na TFD. Essa saturação foi confirmada com a realização das últimas entrevistas, à medida que ocorriam convergências e reincidências temáticas, não surgindo novos dados, novas propriedades e dimensões (STRAUSS; CORBIN, 2008).

O enfoque da teoria fundamentada quanto à coleta e à análise simultânea dos dados permite prosseguir buscando as análises da ação e do processo, ao passo que adaptamos a coleta de dados para construir as análises emergentes (CHARMAZ, 2009).

A codificação constitui-se a etapa inicial para passarmos dos enunciados reais contido nos dados, à construção das interpretações analíticas. Procuramos elaborar uma versão interpretativa que se inicia com a codificação e elucida o fenômeno estudado. Os 
códigos revelam a maneira como selecionamos, separamos e classificamos os dados para começar uma avaliação analítica destes (CHARMAZ, 2009).

O processo de codificação na TFD ocorre pelo método analítico de comparação de dados com categorias que emergem a partir dos dados. Esse processo inclui a comparação das categorias emergentes com novas categorias, e, por fim, compara-se a relação entre categorias, seguindo um processo de codificação não-linear. Nesta codificação, os dados são separados em pequenos fragmentos, que podem ocorrer linha a linha, sentença por frase, ou qualquer outro critério escolhido, para que a unidade de análise adquira significado em si, permitindo a interpretação (BARRETO; GARCIAVIVAR; MARCON, 2018).

Strauss e Corbin (2008) indicam que durante o processo de análise dos dados, a sistematização desta análise passe por três procedimentos para codificação: a codificação aberta, a axial e a seletiva.

A codificação aberta analisou linha por linha, onde originou conceitos, propriedades e dimensões. O termo "aberta" remete ao ato de revelar, nomear e desenvolver conceitos, onde se abre o texto e se expõem pensamentos, ideias e significados contidos no mesmo. É durante a codificação aberta que os dados são separados em partes distintas, rigorosamente examinados e comparados em busca de similaridades e diferenças, sendo agrupados em conceitos mais abstratos, conhecidos por categorias (STRAUSS; CORBIN, 2008).

$\mathrm{Na}$ codificação axial inicia-se o processo de reagrupamento dos dados, divididos durante a codificação aberta. É axial porque ocorre em torno do eixo de uma categoria. Assim, as categorias são relacionadas às suas subcategorias para levantar explicações mais precisas e completas sobre o fenômeno. Uma categoria representa um fenômeno, um problema, uma questão, um fato ou um acontecimento, que foi considerado como importante pelos participantes do estudo (STRAUSS; CORBIN, 2008).

Desta forma, a opção da utilização da TFD ocorreu devido a mesma permitir o desenvolvimento de modelos teóricos explicativos dos fenômenos a serem estudados, constituindo-se numa ferramenta que proporcionará grande contribuição para profissionais de saúde e para questões que norteiam as Políticas de Saúde (NICO et al., 2007).

$\mathrm{Na}$ codificação seletiva, ocorre o processo de integrar e refinar a teoria. $\mathrm{Na}$ integração, as categorias são arranjadas em volta de um conceito explanatório central. A 
integração ocorre com o tempo, iniciando nos primeiros passos da análise, e na maioria das vezes não finaliza até a redação final (STRAUSS; CORBIN, 2008).

Durante todo processo de análise, ao formular questionamentos aos dados como: quem, como, por que, quando e o que, a fim de permitir a codificação teórica, que é a capacidade de selecionar dados que possam trazer luz nova ao desenvolvimento de à teoria emergente, foram utilizadas as ferramentas analíticas propostas por Strauss, Corbin (2008), a saber: memorandos e diagramas. Estes foram sendo acompanhados pela amostragem teórica, saturação teórica e sensibilidade teórica (STRAUSS; CORBIN, 2008).

A análise em TFD é principalmente indutiva, isso significa que os pesquisadores passam do específico para o geral, a fim de explicar fenômenos dentro de um processo de geração de teoria qualitativa (FOLEY; TIMONEM, 2018).

Por fim, é importante destacar que os pesquisadores que utilizam a TFD não só codificam dados para conceitos, mas também identifica relações entre conceitos, categorias e subcategorias para poder construir a teoria substantiva que explica o fenômeno de interesse (FOLEY; TIMONEM, 2018).

Portanto, na ocasião em que o esquema teórico seja destacado, o pesquisador estará pronto para refinar a teoria, enxugando os excessos e completando as categorias mal desenvolvidas, por meio da amostragem teórica adicional. Por fim, a teoria é validada por meio da comparação com dados brutos ou ainda através de sua apresentação aos entrevistados para ver a reação deles (STRAUSS; CORBIN, 2008).

Destaca-se que diante do complexo processo analítico que envolve a teorização, são requisitos fundamentais na pesquisa, a sensibilidade e a empatia do pesquisador. No processo de construção de uma grounded theory faz-se necessário buscar o equilíbrio entre o rigor científico, criatividade e inspiração em movimentos antagônicos, dotados de harmonia e conflito, acerca do que sabemos e o que achamos que sabemos. Portanto, o exaustivo reconhecimento do contraditório é que a teoria pode ser enraizada e sustentada (OLIVEIRA; NAKAUAMA, 2018)

A atenção às pessoas com $\mathrm{TB}$ demanda um cuidado prolongado e que é influenciado por diferentes aspectos, tanto relacionados à pessoa com TB, e sua condição de vida, muitas vezes em situações de vulnerabilidade social, quanto aos relacionados aos serviços de saúde (BRASIL, 2011; WHO, 2014). Percebe-se que o processo de cuidar da pessoa com TB envolve mais do que a entrega de medicamentos e a realização de exames. Há necessidade de um envolvimento efetivo dos profissionais da saúde no cuidado, de 
forma a compreender as repercussões da doença em suas vidas e dos fatores que podem interferir no tratamento, contribuindo para a realização de um cuidado contextualizado à realidade de cada um.

\section{Conclusões}

Estudar o cuidado da pessoa com TB sob a perspectiva dos enfermeiros na atenção básica de saúde, por meio de um estudo qualitativo, utilizando os pressupostos da TFD, possibilitou uma compreensão singular de como esse cuidado estava acontecendo, quem eram os principais protagonistas do mesmo, que dificuldades e situações estavam sendo enfrentadas para efetivar esse cuidado.

Essa compreensão permitiu a construção de um modelo teórico que visualiza o que acontece quando esse cuidado se dá. Assim, a descrição da construção desse estudo poderá nortear pesquisadores quanto ao desenvolvimento de modelos teóricos, com vistas o fortalecimento da qualidade dos relatórios, ao seguir o rigor metodológico do método e utilizar o Atlas TI como ferramenta de organização dos dados analisados.

O desenvolvimento do modelo teórico pode subsidiar a construção de um modelo de cuidado de enfermagem à pessoa com $\mathrm{TB}$, que considere mais efetivamente a realidade dos serviços de saúde e que seja voltado para as demandas, necessidades e direitos da pessoa com TB em seu contexto de vida.

O conhecimento construído com este estudo traz uma nova perspectiva, uma vez que a maioria dos estudos já realizados a que tivemos acesso não focalizou o cuidado na perspectiva dos enfermeiros, mas, sim, situações que dificultavam a atenção e o tratamento da pessoa com TB, contrastando-as com as recomendações nacionais e internacionais. Essas recomendações, por sua vez, também não revelam preocupação com os enfrentamentos dos enfermeiros para concretizar o cuidado, e alcançar não só a cura, mas o restabelecimento de vida e de saúde da pessoa acometida.

A abordagem metodológica da TFD permitiu apropriar-se do fenômeno, a partir das experiências dos participantes do estudo, e não de uma forma pré-concebida ou idealizada de como estava ocorrendo o cuidado à pessoa com TB na atenção básica de saúde. A maneira de coletar e de analisar os dados levou a uma imersão nos acontecimentos que ocorriam para o cuidado materializar-se e alcançar os objetivos pretendidos com o mesmo. 
Portanto, a construção desse modelo teórico relatado permitiu conhecer e refletir sobre a forma como vem ocorrendo o cuidado o que possibilita aos profissionais da saúde e da enfermagem planejar e perpetrar modelos de cuidado que considerem aspectos relevantes para alcançar o restabelecimento da saúde e a cura da doença; como também aos gestores repensar as formas como a política de saúde vem sendo elaborada e implementada.

Como limitação, destacamos que o estudo foi realizado apenas com a participação de enfermeiras com ampla experiência no cuidado à pessoa com TB; e desenvolvido em apenas uma região do município, e do país.

\section{Referências}

BARREIRA, D. Os desafios para a eliminação da tuberculose no Brasil. Epidemiol. Serv. Saude, Brasília, v. 27, n.1, p.1-4, maio. 2018.

BARRETO, M. S.; GARCIA-VIVAR, C.; MARCON, S. S. Methodological quality of Grounded Theory research with families living with chronic illness. International Journal of Africa Nursing Sciences, África, v. 8, n. 1, p 14-22, jan. 2018.

BRASIL. Ministério da Saúde. Secretaria de Vigilância em Saúde. Programa Nacional de Controle da Tuberculose. Tratamento Diretamente Observado (TDO) da Tuberculose na Atenção Básica: Protocolo de enfermagem. Brasília: Ministério da Saúde, 2011.

CAVALCANTE, E.F.O.; SILVA, D.M.G.V. Nurses' commitment to the care of tuberculosis patients. Texto contexto-enferm, Florianópolis, v.25, n. 3, p. 1-10, ago. 2013.

CAVALCANTE, E. F. O. O cuidado do enfermeiro à pessoa com tuberculose na atenção básica de saúde. 2014. Tese (Doutorado em Enfermagem) - Centro de Ciências da Saúde, Universidade Federal de Santa Catarina, Florianópolis, 2014.

CASSIANI, S. H. de B.; CALIRI, M. H. L.; PELÁ, N. T. R. A teoria fundamentada nos dados como abordagem da pesquisa interpretativa. Rev. Latino-Am. Enfermagem, Ribeirão Preto, v. 4, n. 3, p.75-88, dez. 1996.

CHARMAZ, K. A Construção da Teoria Fundamentada- guia prático para análise qualitativa. 1. ed. Porto Alegre: Artmed, 2009.

FOLEY, G.; TIMONEN, V. Using Grounded Theory Method to Capture and Analyze Health Care Experiences. Health Serv Res., Chicago, v. 50, n. 4, p. 1195-210, ago. 2015.

NASCIMENTO, L. de C. N. et al. Saturação teórica em pesquisa qualitativa: relato de experiência na entrevista com escolares. Rev. Bras. Enferm., Brasília, v.71, n. 1, p. 228-233, fev. 2018.

NICO, L. S. et al. A Grounded Theory como abordagem metodológica para pesquisas qualitativas em odontologia. Ciênc. saúde coletiva, Rio de Janeiro, v. 12, n. 3, p. 789-97, jun. 2007. 
OLIVEIRA, P. C.; NAKAYAMA, M. K. Operacionalização de uma grounded theory: o percurso metodológico. Revista Pesquisa Qualitativa, São Paulo, v.6, n.12, p. 572-594, dez. 2018.

PELISSARI, D. M. et al. Oferta de serviços pela atenção básica e detecção da incidência de tuberculose no Brasil. Rev. Saude Publica, São Paulo, v.52, n.1, p. 1-10. 2018.

STRAUSS, A.; CORBIN, J. Pesquisa Qualitativa: técnicas e procedimentos para o desenvolvimento de teoria fundamentada. 2. ed. Porto Alegre: Artmed, 2008.

WHO. TB CARE I. International Standards for Tuberculosis Care. 3. ed. TB CARE I, The Hague: World Health Organization, 2014.

WHO. Global tuberculosis report 2018. Geneva: World Health Organization; 2018.

Recebido em: 20 de fevereiro 2019.

Aceito em: 17 de março de 2019. 